\title{
MEASUREMENT OF SEAWARD GROUND DISPLACEMENTS ON COASTAL LANDFILL AREA USING RADAR INTERFEROMETRY
}

\author{
Won-Kyung Baek ${ }^{1, *}$, Hyung-Sup Jung ${ }^{1}$ \\ ${ }^{1}$ Department of Geoinformatics, University of Seoul, Korea - (bekwkz, hsjung)@uos.ac.kr
}

Commission III, WG III/3

KEY WORDS: SAR, SAR Interferometry, Multiple-Aperture SAR Interferometry, Coastal landfill, Three-dimensional measurements

\begin{abstract}
:
In order to understand the mechanism of subsidence and help reducing damage, researchers has been observed the line-of-sight subsidence on the Noksan industrial complex using SAR Interferometry(InSAR) and suggested subsidence prediction models. Although these researches explained a spatially uneven ground subsidence near the seaside, they could not have been explained the occurrence of the newly proposed seaward horizontal, especially nearly north-ward, displacement because of the geometric limitation of InSAR measurements. In this study, we measured the seaward ground displacements trend on the coastal landfill area, Noksan Industrial Complex. We set the interferometric pairs from an ascending and a descending orbits strip map data of ALOS PALSAR2. We employed InSAR and MAI stacking approaches for the both orbits respectively in order to improve the measurement. Finally, seaward deformation was estimated by retrieving three-dimensional displacements from multi-geometric displacements. As a results, maximally 3.3 and $0.7 \mathrm{~cm} /$ year of ground displacements for the vertical and seaward directions. In further study, we plan to generate InSAR and MAI stacking measurements with additional SAR data to mitigate tropospheric effect and noise well. Such a seaward observation approach using spaceborne radar is expected to be effective in observing the long-term movements on coastal landfill area.
\end{abstract}

\section{INTRODUCTION}

A Noksan industrial complex is coastal landfill where located in western Busan, Korea. The coastal landfill heads to near south direction. A spatially uneven ground subsidence have happened since beginning of construction, because of soft ground foundation(Kim, 2011; Kim et al., 2005; Cho and Lee, 2014). Ground subsidence is the main geological disaster, as it can cause serious damages to the urban components such as; structures, buildings or sanitary sewers(Guo et al., 2016; Luo et al., 2014).

Thus ground displacements monitoring were performed using various in-situ measuring instruments such as settlement plates, differential settlement gauges or clinometers since the construction had been began(Cho and Lee, 2014). However, some early measurements were omitted owing to weak ground foundation. More than $65 \%$ of measuring instruments were destroyed on account of a rapid banking process(Kim, 2001). Therefore, it was difficult to utilize in-situ measurements to analyse long-term settlement (Kim, 2001). Moreover, the recent ground subsidence analysis is difficult since the in-situ measurements were stopped owing to financial limitations(Cho and Lee, 2014).

In order to overcome limitations of in-situ measurements, Multi-temporal differential SAR Interferometry(MTInSAR) was applied(Kim et al., 2005; Jo and Lee, 2014). MTInSAR methods could retrieve time-series line-of-sight(LOS) displacements. These results were also utilized to suggest ground subsidence model(Kim et al. ,2005).

Meanwhile, the probability of seaward horizontal displacements were even suggested because of unsymmetrical surcharges of features on the ground such as buildings, roads or container boxes(Kim, 2001; Hong and Kim, 2012; Cho and Lee, 2014). Seaward displacements could cause serious hazards more than simple cracks. However, line-of-sight measurements, which indicates perpendicular to satellite near polar orbit, could not explain seaward displacements of the Noksan industrial complex since the coastal landfill faces to south direction.

Multiple-aperture SAR Interferometry(MAI) is the method to measure along-track displacements by splitting azimuth SAR raw signal(Bechor and Zebker, 2006). After that, MAI have been gradually improved. Jung's MAI significantly improved the accuracy of along-track measurements(Jung et al., 2009; 2014; 2015). The precision of Jung's MAI was $3 \sim 4 \mathrm{~cm}$ in ideal conditions $(\gamma=0.8)($ Jung et al., 2014). However in real condition, as the temporal baseline is prolonged for accumulating deformation signal, temporal decorrelation increases(Zebker and Villasenor, 1992). Accordingly, the precision of Jung's MAI also not enough to measure a subtle seaward deformation. Recently, efficient MAI stacking methods were suggested(Jo et al., 2015). As a results, north directional displacements, retrieved by combining InSAR stacking and Jo's MAI stacking, could be measured in sub-cm precision(Jo et al., 2015)

In this study, we applied MAI stacking methods to measure seaward(near-north) displacements on the coastal landfill. For the purpose, we performed stacking process to Multi-temporal InSAR and MAI interferograms from ALOS PALSAR-2 both ascending and descending orbits. In succession, we retrieved three-dimensional annual ground displacements(Fialko and Simon, 2001; Jung et al., 2011).

\footnotetext{
* Corresponding author
} 


\section{STUDY AREA AND DATA}

Study area is located on the western Busan. Geologically, the study area were formed by stream sediment, which occupied the depth of $40 \sim 70 \mathrm{~m}$. Long term subsidence on Noksan industrial complex had been expected because of the load of banking and facilities(Kim, 2001). When the load above the soft ground is biased, the horizontal stress is increased and horizontal displacements occurs Hong and Kim, 2012). Horizontal displacements are feasible to cause transformations or destructions of adjacent structures (Kim, 2011). Especially, such transformations or destructions are directly causative of long-term environmental and geological disaster(Guo et al., 2016; Luo et al., 2014). In spite of these danger, the study about seaward horizontal displacements on Noksan industrial complex have hardly performed. Therefore measuring seaward ground deformation on the coastal landfill, Noksan industrial complex, is a very important issue.

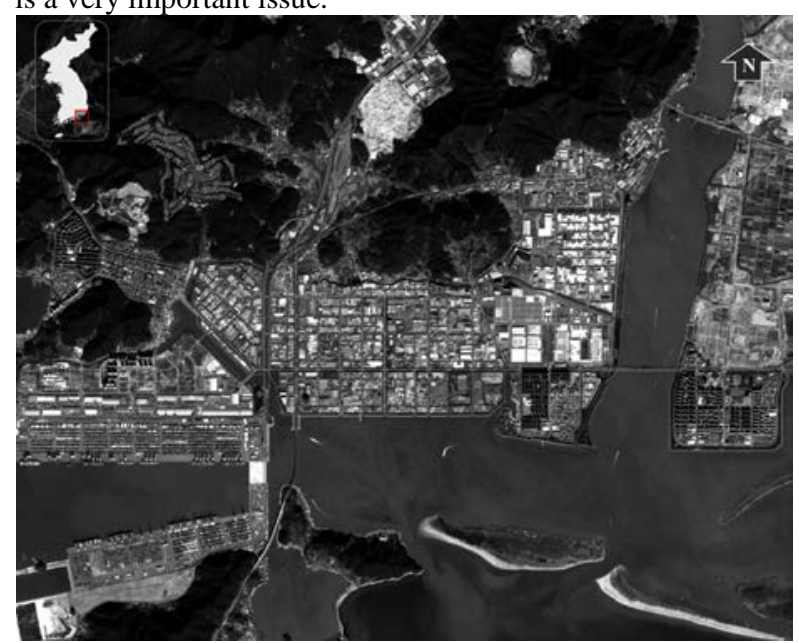

Figure 1. Study area, Noksan industrial complex; A red box on the white map indicates the Location of the study area in

Korean peninsula

To measure subtle seaward displacements on the study area, the level of accuracy is very important. Shorter effective antenna dimension and high(close to 1) coherence are essential parameters to lower MAI accuracy in theory(Jung et al., 2014). Additionally the deformation signal should be accumulated to exceed accuracy level for sufficiently long periods(temporal baseline). Temporal baseline largely affects decorrelation of interferograms. In common scattering theories, long wavelength data are suitable for maintaining high coherence(Zebker and Villasenor, 1992;Hong and Simon, 2011).

The wavelength of ALOS PALSAR-2 is about $23.6 \mathrm{~cm}$, longer than that of other spaceborne SAR sensors. Although azimuth antenna dimension of ALOS PALSAR-2 is $9.9 \mathrm{~m}$ on documents, effective azimuth antenna dimension calculated from SLC and several parameters was $6.37 \mathrm{~m}$ respectively(Jung et al., 2015; Jo et al., 2017). In this respect. we selected L-band ALOS PALSAR-2 single polarization stripmap acquisition. And $12 \mathrm{~m}$ World DEM were used to simulate the topographic effect and mitigates the topographic error.

\section{DATA PROCESSING}

Table 1 showes the interferometric pairs to retrieve seaward displacements. Each pairs were processed by InSAR stacking and MAI stacking(Jo et al., 2015). InSAR interferograms were initially filtered by median and directional filter to mitigate tropospheric and ionospheric error before stacking. Median filter are rarely utilized to reduce tropospheric effects in general. Since we focused on local deformation, however, we applied the filter to reduce spatially random pattern.

Each MAI interferograms were not used in MAI stacking process. Instead, the forward-looking and backward-looking interferograms were stacked respectively. And initial stacked MAI interferograms were generated by subtracting stacked forward- and backward-looking interferograms each other. In succession, we applied directional filter to mitigate ionospheric error(Chae et al., 2017).

\section{RESULT}

Figure 2 shows InSAR and MAI stacking results. Fig. 2(a) and (b) are InSAR stacking maps from ascending and descending orbits. The LOS displacements were clearly measured inside white dashed box. The similar LOS displacements pattern between two InSAR stacking maps indicates that the vertical displacements components were included in each LOS measurements. Fig. 2(c) is the MAI stacking measurements of descending orbits. The MAI stacking map from ascending orbit were too contaminate to measure subtle displacements by severe ionospheric pattern. Descending MAI stacking map also showed much noisier pattern than InSAR because of low coherence of vegetation or construction area. Fortunately, the study area is industrial area, the coherence were relatively high. Therefore the local deformation on the area could be measured.

\begin{tabular}{|c|c|c|c|c|c|}
\hline \multicolumn{2}{|c|}{ Ascending } & \multicolumn{2}{c|}{ Descending } \\
\hline Date & $\begin{array}{c}\text { Perpendicular } \\
\text { baseline (m) }\end{array}$ & $\begin{array}{c}\text { Temporal Baseline } \\
\text { (days) }\end{array}$ & Date & $\begin{array}{c}\text { Perpendicular } \\
\text { baseline (m) }\end{array}$ & Temporal Baseline (days) \\
\hline 20140819 & 195 & 294 & $\begin{array}{l}20150523 \\
20160409\end{array}$ & 202 & 322 \\
\hline 20150609 & -3 & 1008 & $\begin{array}{l}20150523 \\
20170325\end{array}$ & 251 & 672 \\
\hline 20140819 & -290 & 812 & $\begin{array}{l}20151010 \\
20170325\end{array}$ & 200 & 532 \\
\hline 20170523 & -197 & 714 & $\begin{array}{l}20160213 \\
20170325\end{array}$ & 132 & 406 \\
\hline 20170523 & & & 20160409 & 49 & 350 \\
\hline 20150609 & & 20170325 & 49 \\
\hline
\end{tabular}

Table 1. ALOS2 PALSAR2 Interferometric pairs used for this study 


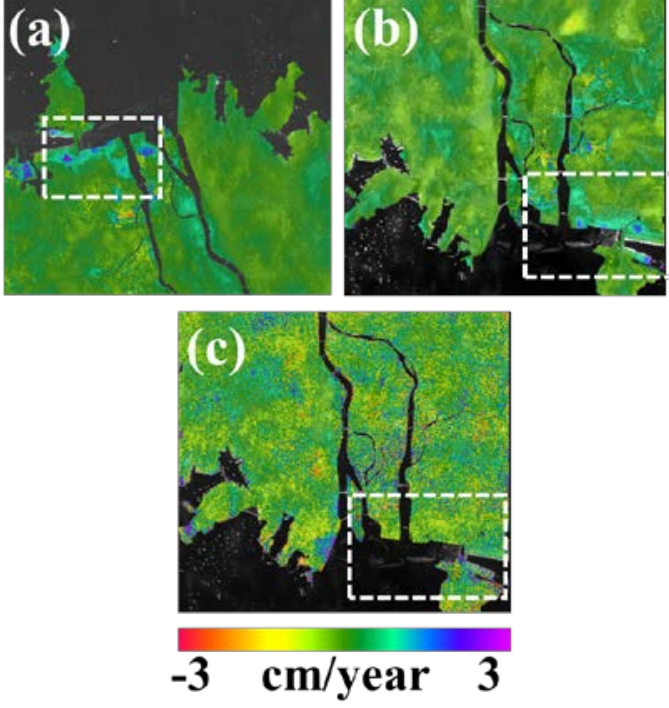

Figure 2. Stacked InSAR and MAI map; (a) ascending InSAR stacking; (b) descending InSAR stacking; (c) descending MAI stacking;

Figure 3 shows three-dimensional surface deformation retrieved from InSAR and MAI stacking measurements. The results showed the ground deformation of 3.3 and $0.7 \mathrm{~cm} /$ year for down and south directions maximally.

Meanwhile the deformation of east-west direction was nearly zero. Seaward deformation could be recognized from threedimensional vector map. The seaward deformation was gradually decreased close to the sea. It would seem that the effects of foundation piles(Kim, 2011)

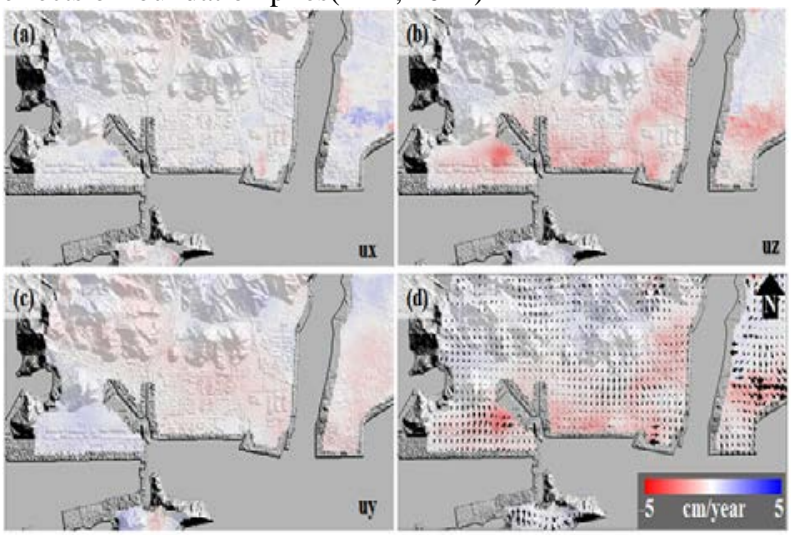

Figure 3. Three-dimensional surface deformations of Noksan industrial complex; (a)-(c) indicate east, up and north directional deformation respectively; (d) three-dimensional vector map; the base map is up-down directional deformation, and the arrows indicate the maginitude and direction of horizontal deformation.

\section{CONCLUSIONS}

We employed InSAR and MAI stacking methods to measure seaward deformation on the coastal landfill, Noksan industrial complex. As a result of retrieving three-dimensional ground deformation, although east-west deformation was almost zero, the valid deformation signal was measured for north-south and up-down directions. In further study, we plan to generate InSAR and MAI stacking measurements with additional SAR data to mitigate tropospheric effect and noise. Such a seaward observation approach using spaceborne radar is expected to be effective in observing the long-term movements on coastal landfill area. In addition, these approach could provide an appropriate approach to the subsidence management of coastal landfills with the free SAR data such as Sentinel-1 and NISAR(Scheduled to be launched in 2021).

\section{ACKNOWLEDGEMENTS}

This study was funded by the Korea Meteorological Administration Research and Development Program [Grant number KMI2017-9060]. And the ALOS PALSAR-2 data used in this study are owned by Japan Aerospace Exploration Agency(JAXA), and the ALOS PALSAR-2 data were provided through the JAXA's ALOS-2 research program(RA4, PI No. 1412).

\section{REFERENCES}

Kim, M., 2001. Settlement Characteristics of Sand Deposits in the Mouth of Nakdong River, Donga university, Busan, Korea(in Korean).

Kim, J.-H., 2011. A study on buried pipes placed in marine reclaimed soft ground undergoing lateral movement, ChungAng University, Seoul. Korea(in Korean).

Hong, W.-P. and Kim, J.-H., 2012. Characteristics of Lateral Flow due to Embankments for Road Construction on Soft Grounds Using Vertical Drain Methods, Journal of the Korean geotechnical society, 28(9), pp. 5-15(in Korean),

Cho, M.-J. and Lee, C.-W., 2014. Ground Subsidence Measurements of Noksan National Industrial Complex using Cband Multi-temporal SAR images. Korean Journal of Remote Sensing, 30(2), pp. 161-172(in Korean).

Kim, S.-W., Lee, C.-W., Song, K.-Y., Min, K.-D. and Won, J.S., 2005. Application of L-band differential SAR interferometry to subsidence rate estimation in reclaimed coastal land. International journal of remote sensing, 26(7), pp.1363-1381.

Bechor, N. B. and Zebker, H. A., 2006. Measuring twodimensional movements using a single InSAR pair. Geophysical research letters, 33(16).

Jung, H.-S., Won, J.-S. and Kim, S.-W., 2009. An improvement of the performance of Multiple-Aperture SAR Interferometry (MAI). IEEE Transactions on Geoscience and Remote Sensing, 47, pp. 2859-2869.

Jung, H.-S., Yun, S.-H. and Jo, M.-J., 2015. An improvement of multiple-aperture SAR interferometry performance in the presence of complex and large line-of-sight deformation. IEEE Journal of Selected Topics in Applied Earth Observations and Remote Sensing, 8, pp. 1743-1752.

Jo, M.-J., Jung, H.-S., Won, J. -S., Poland, M. P., Miklius, A. and $\mathrm{Lu}, \mathrm{Z}$., 2015. Measurement of slow-moving along-track displacement from an efficient multiple-aperture SAR interferometry (MAI) stacking. Journal of Geodesy, 89(5), pp. 411-425.

Jo, M.-J., Jung, H.-S. and Yun, S.-H., 2017. Retrieving Precise Three-Dimensional Deformation on the 2014 M6.0 South Napa 
The International Archives of the Photogrammetry, Remote Sensing and Spatial Information Sciences, Volume XLII-3, 2018 ISPRS TC III Mid-term Symposium "Developments, Technologies and Applications in Remote Sensing", 7-10 May, Beijing, China

Earthquake by Joint Inversion of Multi-Sensor SAR. Scientific Reports, doi.org/10.1038/s41598-017-06018-0.

Jung, H.-S., Lee, W.-J., and Zhang, L., 2014. Theoretical accuracy of along-track displacement measurements from multiple-aperture interferometry (MAI). Sensors, 14(9), pp. 17703-17724.

Jung, H.-S., Lu, Z., Won, J. -S., Poland, M. P. and Miklius, A., 2011. Mapping three- dimensional surface deformation by combining multiple- aperture interferometry and conventional interferometry: Application to the June 2007 eruption of Kilauea volcano, Hawaii. IEEE Geoscience and Remote Sensing Letters, 8(1), pp. 34-38.

Chae, S.-H., Lee, W.-J., Jung, H.-S. and Zhang, L., 2017. Ionospheric Correction of L-Band SAR Offset Measurements for the Precise Observation of Glacier Velocity Variations on Novaya Zemlya. IEEE Journal of Selected Topics in Applied Earth Observations and Remote Sensing, 10(8), pp. 3591-3603.

Hong, S.-H. and Wdowinski, S., 2011. Interferometric coherence analysis with high resolution space-borne synthetic aperture radar. In : 2011 IEEE 3rd International Asia-Pacific Conference on Synthetic Aperture Radar (APSAR), pp. 1-2.

Zebker H.A. \& Villasenor J. (1992) Decorrelation in interferometric radar echoes. IEEE Transactions on geoscience and remote sensing, 30(5): 950-959.

Guo, J., Zhou, L., Yao, C. and Hu, J., 2016. Surface Subsidence Analysis by Multi-Temporal InSAR and GRACE: A Case Study in Beijing. Sensors, 16(9), p. 1495.

Luo, Q., Perissin, D., Lin, H., Zhang, Y. and Wang, W., 2014. Subsidence monitoring of Tianjin suburbs by TerraSAR-X persistent scatterers interferometry. IEEE Journal of Selected Topics in Applied Earth Observations and Remote Sensing, 7(5), pp. 1642-1650 